\title{
Self-assessment of Polish pharmacy staff's readiness to promote health
}

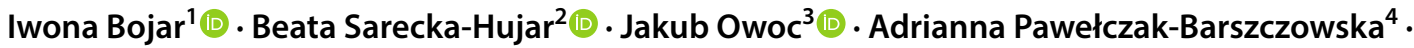 \\ Dorota Raczkiewicz ${ }^{5}$ (1)
}

Received: 27 January 2020 / Revised: 22 June 2020 / Accepted: 7 July 2020 / Published online: 9 August 2020

(c) The Author(s) 2020

\begin{abstract}
Background Nowadays, pharmacists are expected to focus not only on dispensing medicines but also on the wellness of the patient. In some developed countries a pharmacist is clearly defined as a health care professional that can make a contribution to improving the general health of the population. Objective To assess the readiness of Polish pharmacy staff to engage in health promotion and educational activities. Setting Community pharmacies in Poland. Method The study group consisted of 308 pharmacy staff ( 248 pharmacists and 60 pharmacy technicians) employed in Polish pharmacies. The survey questionnaire referred to three domains: systemic solutions for health promotion, readiness of pharmacy staff as a professional group to promote health, personal readiness to promote health. Responses about pharmacy staff's readiness to promote health were scored using a 10-point scale. Scale reliability for all items (overall readiness), and for items within the three domains separately, were tested using Cronbach's $\alpha$ and average inter-correlation coefficient among the items. Main outcome measure Pharmacy staff's readiness to promote health (the questionnaire containing 32 items). Results The overall readiness of pharmacy staff to promote health was rather low (average of 4.6 \pm 1.5 in 1-10 scale). The highest scores were obtained for pharmacy staff's personal readiness to promote health (average of $5.5 \pm 1.8$ ) which was neutral on the scale. The lowest scores were obtained for systemic solutions for health promotion (average of $3.6 \pm 1.4$ ). Readiness of pharmacy staff as a professional group was ranked in the middle (average $4.8 \pm 1.8$ ). Surveyed pharmacy staff rated their readiness to promote health in the work environment significantly higher than promoting health in the local community. Female and younger pharmacy staff as well as those with job seniority of less than 5 years, or pharmacy technicians assessed their readiness to promote health significantly higher than others. Readiness to promote health was higher among pharmacy staff working in pharmacies employing up to 3 staff members and at pharmacies with over 200 customers daily. Conclusions The overall readiness of pharmacy staff to promote health was low, especially in the domain of systemic solutions in health promotion.
\end{abstract}

Keywords Health promotion $\cdot$ Health education $\cdot$ Pharmacists $\cdot$ Pharmacy $\cdot$ Poland $\cdot$ Readiness

Beata Sarecka-Hujar

bsarecka-hujar@sum.edu.pl

1 Department of Women's Health, Institute of Rural Health, ul. Jaczewskiego 2, 20-090 Lublin, Poland

2 Department of Basic Biomedical Science, School of Pharmacy with the Division of Laboratory Medicine in Sosnowiec, Medical University of Silesia in Katowice, Kasztanowa Str 3, 41-200 Sosnowiec, Poland

3 Gerontology, Public Health and Education Department, National Institute of Geriatrics, Rheumatology and Rehabilitation in Warsaw, Spartańska Str 1, 02-637 Warsaw, Poland

4 Zentiva, Warsaw, Poland

5 Institute of Statistics and Demography, Collegium of Economic Analysis, SGH Warsaw School of Economics, Al. Niepodległości 162, 02-554 Warsaw, Poland

\section{Impacts on practice}

- Polish pharmacy staff's readiness to promote health requires further improvement especially in terms of systemic solutions and satisfying patients' health needs, using all available methods (legal, economic, etc.).

- Financial support is needed to encourage pharmacies to engage in health promotion and health education activities, both in the workplace and the local community.

- Pharmacists should be encouraged to perceive themselves as health care professionals who can promote health and conduct health education in the local community. 
- The educational curricula for pharmacists and pharmacy technicians should cover public health issues such as health promotion and health education.

\section{Introduction}

Disease prevention and health promotion are key instruments in improving community health and are a high priority within the European Union. Nevertheless, actions aimed at fostering healthy lifestyles are complex and require the involvement of all healthcare professionals including pharmacists. Their responsibilities in this area have been dynamically evolving as pharmaceutical care directs more of its focus on the needs of a patient rather than the dispensing of drugs [1]. There is an increasing need for pharmacists to be involved in screening for health conditions, vaccination programs, and to act as primary care specialists because they are often the first point of contact for patients [2-5]. A Sudanese study demonstrated that $70 \%$ of the surveyed pharmacists were ready to engage in public health activities and expressed a desire to develop skills aimed at modifying patient behaviors [6]. In Anglo-saxon countries, pharmacists play an important role in the process of immunization and vaccination education. In the United States, pharmacists have been participating in vaccinations for influenza and measles for many years [7]. According to the American Pharmacists Association, 320,000 pharmacists have been trained to administer vaccines [8]. A study by Westrick et al. [9] indicated that most public pharmacies in the US offer at least one type of vaccine. In Poland, the competence of pharmacists do not cover vaccinations. In a meta-analysis by Isenor et al. [10] the impact of pharmacists on vaccination rates was evaluated. The study found the pharmacist's involvement in the vaccination process as educators or vaccinators, which resulted in increased vaccine use. This may be due to the fact that the pharmacist is often the first and sometimes the only representative of the healthcare service with which the patient has contact. According to Jones et al. [11] the pharmacy profession enjoys one of the highest levels of trust among all professions. On the other hand, in a Polish study of Warsaw pharmacies, to determine when a patient seeks the help of a pharmacist, showed that $76 \%$ of respondents rarely, if ever, visited a pharmacy for purposes of a consultation with a pharmacist [12].

A pharmacist is clearly defined in some developed countries as a health care professional that can make a contribution to improving the health of the population [13-15]. British pharmacists are required to advice their clients on healthy lifestyle, well-being and provide information on how to stop smoking [13]. In Scotland, community pharmacists advise on sexual health [14]. In 2017, Public Health England, a governmental agency, published a document outlining a wide variety of actions that play a vital role in protecting and improving population health that should be performed by pharmacists [15].

The Pharmaceutical Group of the European Union describes the role of a pharmacists in improving public health and indicates ways to achieve such goal to benefit individuals, families and communities [16]. According to the Polish Act "Pharmaceutical Law", pharmacies are defined as institutions of public health protection [17]. There is however, a need for legal and systemic changes in the healthcare system that would allow pharmacy personnel the full usage of their potential in delivering pharmaceutical services related to public health such as promoting healthy behaviors or primary and secondary disease prevention. The literature recommends involving pharmacists in a wide range of healthcare services: prevention, health education or support in overcoming addictions [18-21]. It is also suggested that they may contribute to reducing health inequalities [22], reducing costs and increasing the effectiveness of treatments and improving medical care in general [5]. Pharmacists from various countries are aware of the need to engage in health promotional activities, but also of the need for continuous education in that respect [23]. This is especially the case with community pharmacist who participate in such training less frequently than the hospital ones [24].

From 1990 to 2012, the number of pharmacies in Poland increased over 3.5 times. During this period, chain pharmacies began to develop rapidly, forcing small family pharmacies out of the market. Since 2012, a decrease in the number of pharmacies has been noted, especially from 2017, when new laws were adopted. In order for a pharmacy to be opened there must be at least 3000 local residents and must be at least $500 \mathrm{~m}$ from an existing one, and its owner must be a pharmacist or a company of pharmacists [25]. According to Statistics Poland, there are over 2600 patients per pharmacy in Poland, which is over 1.6 times less than the European average [26]. In Poland, there are 70 pharmacists per 100,000 residents, while this average is 82 for OECD countries. Thus, there are too many pharmacies in Poland and too few pharmacists (on average 1.8 pharmacists per one pharmacy, while the European average is 2.4) [26]. The duration of pharmaceutical studies in Poland is 5.5 years with six months of professional practice in a pharmacy. Pharmacy staff also include pharmacy technicians who have completed a 2.5 -year course with another 2 years of practice in a pharmacy, and can perform similar activities as pharmacists with the exception of dispensing narcotic and psychotropic substances, but they must work under the supervision of a pharmacist. 


\section{Aim of the study}

The objective of the present study was to evaluate readiness of pharmacy staff working in Poland to perform health promotion and education activities.

\section{Ethics approval}

The present survey, involving human participants, was in accordance with the ethical standards of the institutional bioethics committee and the Helsinki declaration (1964). In Poland, surveys are not considered as medical research and do not require the formal approval of a Local Ethics Committee. Participation in the study was anonymous and voluntary, all pharmacy staff gave their verbal consent.

\section{Methods}

\section{Study group}

The study group consisted of pharmacy staff-pharmacists and pharmacy technicians - who have a direct contact with patients and dispense medications in Poland. The survey was conducted in 2017 in community pharmacies in the Lublin region in Poland. Community pharmacies in this region are representative of community pharmacies in the other 15 regions in Poland, as they all function in the same manner and are governed by the same legal regulations. In 2017, in the Lublin region there were 865 pharmacies listed on the National Health Fund (NHF) Lublin Region website. Due to some financial and organizational limitations, 140 pharmacies from this list were selected for the study, which constitutes $16 \%$ of all pharmacies in Lublin region. A systematic sample of pharmacies was selected, where every sixth pharmacy from the NHF list was chosen. Each selected pharmacy was sent 5 copies of the survey questionnaire and asked to fill it in by the pharmacy staff. The total of 368 survey questionnaires were sent back to us. The response rate was $52 \%$. A total number of 308 correctly completed questionnaires were included in the study.

\section{Survey questionnaire}

The survey questionnaire contained 3 sections. The first section referred to the characteristics of pharmacy staff: gender, age, level of education, job seniority. The second section referred to the characteristics of pharmacies: number of staff, location, number of customers daily. In the third section, we adopted the Scale of Social Readiness by Gaś [27] to self-assess Polish pharmacy staff's readiness to promote health. Generally, this scale is used to research various social groups' attitudes to the prevention of different social issues. Our questionnaire included 32 items in three domains: systemic solutions for health promotion (16 items), readiness of a professional group (10 items) and personal readiness to promote health (6 items). Systemic solutions are related to relevant legal acts, certain activities undertaken by pharmacists, organizations and institutions, cooperation between various professional groups and financial support of health promotion in pharmacies in Poland. The readiness to promote health by the pharmacy staff as a professional group is determined by the following questions: are pharmacists as a professional group prepared to promote health in terms of knowledge and methodology, and whether they have motivation, space, organizational and interpersonal skills. In turn, personal readiness of pharmacy staff to promote health is demonstrated by the following questions: are they personally ready and committed, and whether they have organizational and interpersonal skills to promote health.

All items were rated on a 1-10 scale where: 1 equaled a 'definitely no' and 10 equaled a 'definitely yes'. The middle of the scale was set at 5.5 so replies statistically significantly lower than 5.5 were considered as negative, replies statistically significantly higher than 5.5 were considered as positive and replies statistically not significantly different from 5.5 were considered as neutral (neither positive nor negative).

We tested scale reliability for all 32 items and for items within the three domains separately: systemic solutions for health promotion, readiness of a professional group and personal readiness to promote health. We used Cronbach's $\alpha$ and average inter-correlation coefficient among the items $r$.

The total scale of pharmacy staff's readiness to promote health had $\alpha=0.956$ and $r=0.426$. The individual domains had the following scores: systemic solutions for health promotion at $\alpha=0.938$ and $\mathrm{r}=0.503$, readiness of the professional group to promote health at $\alpha=0.928$ and $r=0.585$ and personal readiness to promote health at $\alpha=0.899$ and $r=0.629$. The factor analysis confirmed the extraction of three domains that explained $61.7 \%$ of the total item variance. Cronbach's $\alpha$ values above 0.7 , strong inter-correlations among the items and high percentage of total item variance indicate high reliability and internal coherence of the total scale and the three domains.

\section{Statistical methods}

The statistical analysis was conducted with STATISTICA 12 software (Statsoft, Poland). The absolute numbers (n) and percentages (\%) were estimated for the categorical variables. Arithmetic mean (M) and standard deviation (SD) were estimated for continuous variables. The following statistical tests were used: 
- one sample $t$ test against a value of 5.5 to check whether readiness to promote health is neutral or statistically significantly positive or significantly negative,

- two paired samples $t$ test to compare readiness to promote health between at workplace and in local community,

- two unpaired samples $t$ test to compare readiness to promote health between men and women,

- F-test analysis of variance to compare readiness to promote health between 3 levels of education, 4 intervals of job seniority, 3 intervals of number of employees, 4 locations of pharmacies, 3 intervals of average number of customers daily,

- Pearson's correlation coefficient $r$ to correlate readiness to promote health with age of pharmacy staff.

The significance level was assumed at 0.05 .

\section{Results}

\section{Characteristics of pharmacy staff and pharmacies}

The characteristics of pharmacy staff and pharmacies are presented in Table 1 . The surveyed group consisted of pharmacy technicians (19.5\%), masters of pharmacy (63\%), postgraduate education, professional specialization or Ph.D. in pharmacy (17.5\%).
The pharmacy staff's age ranged from 21 to 65 with the average of $38.0 \pm 11.1$ years. The participants were mostly women (91\%), with a university degree in pharmacy (63\%), with 5-14 years of job seniority (44\%). Most pharmacies employed 4-5 employees (46\%) and were located near a healthcare provider (59\%). Half of all pharmacies served $100-200$ customers daily on average.

\section{Assessment of pharmacy staff's readiness to promote health}

The replies to questions that referred to systemic solutions for health promotion had an average of 2.7-4.4 points in 1-10 scale, which was statistically significantly below the middle i.e. were rated negatively (Table 2 ). The lowest ratings referred to: financial support for health promotion, pharmacy leaders in health promotion, cooperation between professional groups in health promotion and using research results in health promotion (average scores of 2.7-3.1). Participants rated higher: ideas, examples and technical solutions for health promotion (average scores of 3.4-3.5). The highest ratings referred to: strategy, legal regulations, concept of health promotion, as well as institutional and professional support (average scores of 4.0-4.6).

Table 3 shows readiness of pharmacy staff as a professional group to promote health. The highest ratings referred to positive motivation to actively promote health
Table 1 Characteristics of pharmacy staff and pharmacies studied

\begin{tabular}{|c|c|c|c|}
\hline Characteristics of & Variable, parameter & Category/IU & Result \\
\hline \multirow[t]{11}{*}{ Pharmacy staff } & Total sample, $\mathrm{N}$ & - & $308(100.00)$ \\
\hline & \multirow[t]{2}{*}{ Gender, n (\%) } & Women & $279(90.58)$ \\
\hline & & Men & $29(9.42)$ \\
\hline & Age, $\mathrm{M} \pm \mathrm{SD}$ & Years & $38.0 \pm 11.1$ \\
\hline & \multirow[t]{3}{*}{ Level of education, $\mathrm{n}(\%)$} & Pharmacy technicians & $60(19.48)$ \\
\hline & & Masters of pharmacy & $194(62.99)$ \\
\hline & & $\begin{array}{l}\text { Postgraduate education, professional } \\
\text { specialization or Ph.D. }\end{array}$ & $54(17.53)$ \\
\hline & \multirow[t]{4}{*}{ Job seniority, n (\%) } & Below 5 years & $72(23.38)$ \\
\hline & & $5-14$ years & $136(44.16)$ \\
\hline & & $15-25$ years & $48(15.58)$ \\
\hline & & Over 25 years & $52(16.89)$ \\
\hline \multirow[t]{10}{*}{ Pharmacies } & \multirow[t]{3}{*}{ Number of staff, n (\%) } & Up to 3 & $50(16.23)$ \\
\hline & & $4-5$ & $141(45.78)$ \\
\hline & & Over 5 & $117(37.99)$ \\
\hline & \multirow[t]{4}{*}{ Location, n (\%) } & Near a healthcare provider & $182(59.09)$ \\
\hline & & Urban area with high pedestrians traffic & $61(19.81)$ \\
\hline & & Residential area & $29(9.42)$ \\
\hline & & Other & $36(11.69)$ \\
\hline & \multirow{3}{*}{$\begin{array}{l}\text { Daily average number of } \\
\text { clients, n (\%) }\end{array}$} & Below 100 & $97(31.49)$ \\
\hline & & $100-200$ & $153(49.68)$ \\
\hline & & Over 200 & 58 (18.83) \\
\hline
\end{tabular}


Table 2 Assessment of systemic solutions for health promotion

\begin{tabular}{|c|c|c|c|c|}
\hline Question & M & SD & $\mathrm{t}^{\mathrm{a}}$ & $p$ \\
\hline $\begin{array}{l}\text { Is implementation of executive regulations and other guidelines for pharmacy staff in health promotion enforced } \\
\text { by the pharmacy's supervision body or professional associations? }\end{array}$ & 4.6 & 2.6 & -6.075 & $<0.001$ \\
\hline $\begin{array}{l}\text { Is there a clearly defined (in your professional environment of pharmacy staff) concept of health promotion that } \\
\text { includes prophylactics, local health policy and health education? }\end{array}$ & 4.4 & 2.1 & -9.193 & $<0.001$ \\
\hline $\begin{array}{l}\text { Are there institutions or organizations that provide professional training for pharmacy staff in the area of health } \\
\text { promotion, including health education? }\end{array}$ & 4.3 & 2.2 & -9.573 & $<0.001$ \\
\hline Are there clear regulations that define and support a role of pharmacy staff in health promotion? & 4.2 & 2.1 & -10.864 & $<0.001$ \\
\hline $\begin{array}{l}\text { Does pharmacy professional association take actions aimed at improving competence of pharmacy staff as health } \\
\text { promoters and at setting legal-organizational framework for such activities? }\end{array}$ & 4.1 & 2.2 & -11.168 & $<0.001$ \\
\hline $\begin{array}{l}\text { Is there any coordinated work among pharmacy staff on strategy for health promotion by pharmacy staff on a } \\
\text { regional, local and institutional level? }\end{array}$ & 3.9 & 2.3 & -12.209 & $<0.001$ \\
\hline $\begin{array}{l}\text { Are there any institutions/organization that try in an orderly manner to cooperate with pharmacy staff and sup- } \\
\text { port them in activities aimed at health promotion? }\end{array}$ & 3.8 & 2.1 & -14.207 & $<0.001$ \\
\hline $\begin{array}{l}\text { Do pharmacy staff have benchmark solutions for activities aimed at health promotion that can be used to work } \\
\text { out their own health-educational programs? }\end{array}$ & 3.5 & 2.0 & -17.550 & $<0.001$ \\
\hline $\begin{array}{l}\text { Do pharmacy staff have a working concept of coordinated activities aimed at assessing quality and effectiveness } \\
\text { of health promotion activities performed by them? }\end{array}$ & 3.4 & 1.9 & -19.397 & $<0.001$ \\
\hline $\begin{array}{l}\text { Is there an effective system of support for pharmacy staff that delivers technical concepts for health promotion, } \\
\text { technical support and information materials? }\end{array}$ & 3.4 & 1.8 & -20.475 & $<0.001$ \\
\hline $\begin{array}{l}\text { Is it a common practice among pharmacy staff to use results of epidemiological and demographic research to } \\
\text { plan activities in the area of health promotion and information? }\end{array}$ & 3.1 & 1.6 & -26.325 & $<0.001$ \\
\hline $\begin{array}{l}\text { Are there among pharmacy staff on a regional and local level people who may be considered spokespersons or } \\
\text { leaders of the "Pharmacy promoting health" concept? }\end{array}$ & 3.1 & 1.8 & -23.400 & $<0.001$ \\
\hline $\begin{array}{l}\text { Does pharmacy professional association take any action aimed at working out a financial framework for such } \\
\text { activities? }\end{array}$ & 3.1 & 1.8 & -23.400 & $<0.001$ \\
\hline $\begin{array}{l}\text { Is there cooperation between local communities, local and central administration, and pharmacy staff focused on } \\
\text { prophylactics/prevention of drug dependence and addiction, and on monitoring self-treatment? }\end{array}$ & 3.0 & 1.8 & -24.375 & $<0.001$ \\
\hline $\begin{array}{l}\text { Is there a system of financial support for pharmacies in performing health promotion activities, including health } \\
\text { education, at workplace? }\end{array}$ & 2.7 & 1.9 & -25.863 & $<0.001$ \\
\hline $\begin{array}{l}\text { Is there a system of financial support for pharmacies in performing health promotion activities, including health } \\
\text { education, with local communities? }\end{array}$ & 2.7 & 1.9 & -25.863 & $<0.001$ \\
\hline
\end{tabular}

Scale 1-10 where: 1 equaled to 'definitely no' and 10 equaled to 'definitely yes'

$M$ mean, $S D$ standard deviation

${ }^{\text {a } O n e ~ s a m p l e ~} t$ test against a test value of 5.5

including health education both at workplace and in a local community (average score of 5.7 and 5.5, respectively, not statistically significantly different from the middle of scale). Lower ratings referred to 'knowledge and its communication' and 'conditions (premises, organizational and interpersonal, professional group's initiatives to promote health), that were rated significantly below the middle of scale.

We found that the pharmacy staff preferred promoting health at the workplace rather than in the local community $(\mathrm{p}<0.05)$.

The questions that referred to self-perceived readiness to promote health are presented in Table 4 . The pharmacy staff rated highest their readiness to recognize and meet health expectations of customers, social need for health promotion and interpersonal relations facilitating such services (average scores of 5.8-6.0). They rated lower their organizational abilities and proper facilities (4.9) and readiness to perform such tasks with local community (5.1).

In Table 5 we calculated the overall ratings of the three domains: the systemic solutions for health promotion (as a mean of 16 items in this domain), the readiness of a professional group (as a mean of 10 items in this domain) and the personal readiness to promote health (as a mean of 6 items in this domain). We also calculated an overall score of the assessment of pharmacy staff's readiness to promote health as a mean of 3 domains mentioned above.

The overall readiness of pharmacy staff to promote health was low (average of $4.6 \pm 1.5, \mathrm{t}=-14.044, p<0.001$ ). The highest scores referred to pharmacy staff's personal readiness to promote health (average of $5.5 \pm 1.8, \mathrm{t}=0.271, p=0.786$ ) which was in the neutral area on the scale. The lowest scores referred to systemic solutions for health promotion (average of 3.6 $\pm 1.4, \mathrm{t}=-23.227, p<0.001$ ). Readiness of professional 


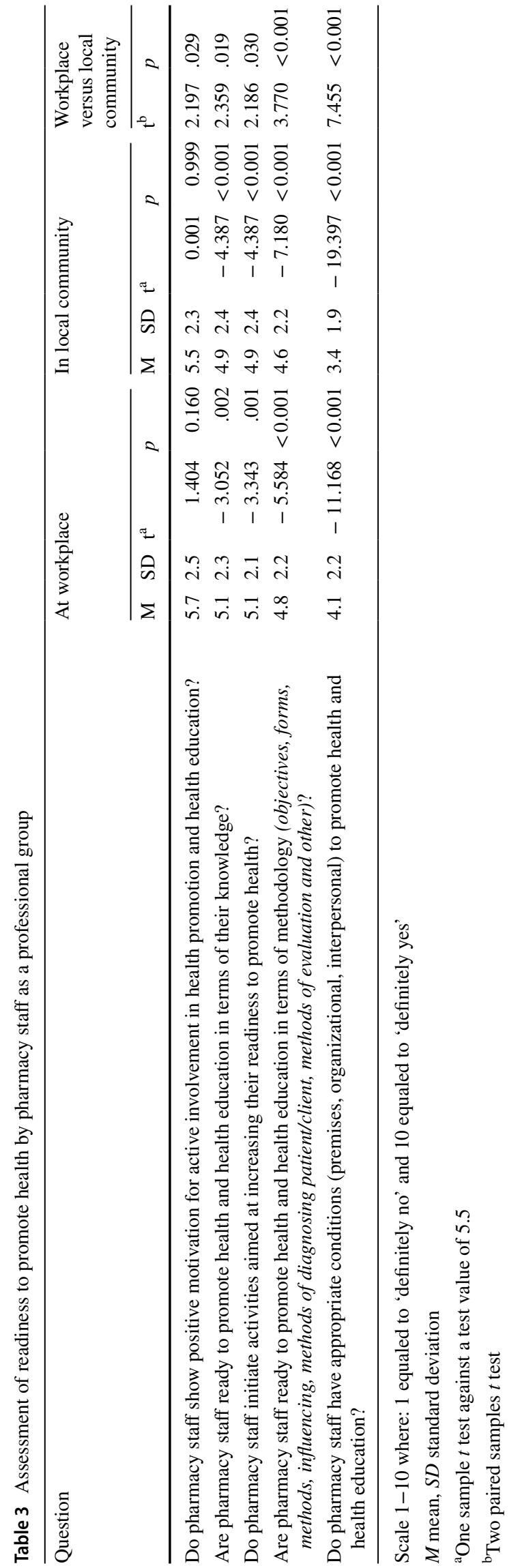

group to promote health was ranked in the middle (average of $4.8 \pm 1.8, \mathrm{t}=-6.521, p<0.001)$.

There were statistically significantly positive correlations: between ratings of systemic solutions for health promotion and readiness of pharmacy staff as a professional group $(\mathrm{r}=0.695, p<0.001)$, between ratings of systemic solutions for health promotion and personal readiness $(r=0.542$, $p<0.001$ ), between personal and professional group's readiness $(\mathrm{r}=0.800, p<0.001)$. It shows that higher scores in one domain translated into higher average scores in other domains of readiness to promote health.

\section{Correlation of pharmacy staff and pharmacies characteristics with/to pharmacy staff's readiness to promote health}

In Table 5 we used the overall scores for the whole questionnaire and scores of 3 domains to correlate them with the respondents' and pharmacies' characteristics. Women rated the systemic solutions for health promotion higher than men (3.7 vs. $2.7, \mathrm{p}<0.001)$, however the assessment of other domains did not correlate to gender $(p>0.05)$. Age of respondents correlated negatively with their overall readiness to promote health and assessment of the three domains: systemic solutions, personal readiness and readiness of a professional group $(\mathrm{r}<00, p<0.05)$. The younger the pharmacists the higher were the average scores of readiness to promote health.

Pharmacy technicians rated significantly better than pharmacists with university or post-university education the following: systemic solutions (4.4 vs. 3.4 or 3.4 , $p<0.001$ ), readiness of the professional group (5.5 vs. 4.7 or $4.7, p=0.008)$ and overall readiness (5.3 vs. 4.5 or 4.7 , $p=0.021$ ). Respondents with the shortest job seniority (up to 5 years) rated overall readiness to promote health and in three domains, significantly better than others $(p<0.001)$.

Pharmacy staff from small pharmacies (up to 3 employees) rated overall readiness to promote health and in three domains, statistically significantly better than pharmacy staff from larger pharmacies (4-5 employees or $>5$ employees). No correlation was found between location of a pharmacy and: overall readiness, systemic solutions, personal readiness and readiness of the professional group ( $p>0.05)$. Pharmacy staff from pharmacies serving below 100 clients a day rated overall readiness to promote health and in three domains, statistically significantly lower than pharmacy staff from pharmacies serving 100-200 or more than 200 clients a day.

\section{Discussion}

The data on how pharmacists perceive their role in health promotion, education and disease prevention is necessary for developing an effective public health program for 
Table 4 Assessment of personal readiness to promote health

\begin{tabular}{|c|c|c|c|c|}
\hline Question & M & SD & $\mathrm{t}^{\mathrm{a}}$ & $p$ \\
\hline $\begin{array}{l}\text { Do you think you are ready to recognize and meet health expectations of patients/pharmacy clients to a } \\
\text { larger extent than it is necessary for regular buy/sell relations? }\end{array}$ & 6.0 & 2.2 & 3.989 & $<0.001$ \\
\hline Do social attitudes and personal relationships at workplace favor health promotion and health education? & 5.9 & 2.4 & 2.925 & .003 \\
\hline Do you think you are effective at health promotion? & 5.8 & 2.0 & 2.632 & .008 \\
\hline Is the level of your readiness to promote health at your workplace sufficient for effective actions? & 5.4 & 2.0 & -0.877 & 0.380 \\
\hline Is the level of your readiness to promote health at your local community sufficient for effective actions? & 5.1 & 2.1 & -3.343 & .001 \\
\hline Do you have appropriate premises and organizational setting for health promotion activities? & 4.9 & 2.4 & -4.387 & $<0.001$ \\
\hline
\end{tabular}

Scale 1-10 where: 1 equaled to 'definitely no' and 10 equaled to 'definitely yes'

$M$ mean, $S D$ standard deviation

${ }^{a}$ One sample $t$ test against a test value of 5.5

pharmacies. Such a discussion intensified in the late 1990s. A study by O'Loughlin et al. [28] from Canada indicated that very few pharmacists discussed disease-prevention with their customers on a routine basis. Nevertheless, over $90 \%$ of them believed that adding preventive healthcare to their practices would be very important but was limited by lack of time and skills.

In the present study we aimed to determine the readiness of Polish pharmacists to promote health and provide health education.

The areas that participants were least positive about were as follows: financial support, leadership, cooperation between professions and failure to apply the results of scientific research. The involvement of pharmacists in health promotion and preventive measures may support public health by lowering costs of patient care and therapies. Poland strives for pharmacists to extend their role in public health in areas such as promotion of healthy behaviors as well as primary and secondary prevention of diseases. Involvement of pharmacists also helps improve patient compliance and the lowering of risks and drug related adverse events and interactions. Positive motivation towards active involvement in health promotion (at workplace and within local communities) was highly rated by the pharmacists in the study. Other aspects of their readiness such as professional and methodological knowledge, appropriate premises or soft skills were rated significantly lower. The readiness to promote health at workplace is significantly higher than within a local community.

The study by Mohamed et al. [6] indicated that almost $90 \%$ of pharmacists provided patients with information on healthy diet while $80 \%$ educated them on obesity and body mass reduction. In Kuwait, pharmacists are likely to involve in advising patients on recommended medication use, potential side effects and lifestyle, although less so to advice on healthy behaviors [29]. However, while a vast majority is willing to learn more about promoting health, they indicate lack of time as a major obstacle. Pharmacists from Riyadh in Saudi Arabia are one of the most trusted professions in understanding needs of society [30]. This is achieved through frequent interactions with patients and customers because pharmacists are often the first and sometimes the only health care professional for many. Nevertheless, they are reluctant to educate patients on oral health although they have proper knowledge [30].

The pharmacy staff in the present study assigned the highest scores to their own "readiness to promote health" followed by "social attitude/interpersonal relationships at workplace that favor health promotion". The lowest scores were assigned to appropriate premises and conditions to promote health and pharmacy staff's own readiness to promote health outside of workplace.

The lowest ratings were assigned to "appropriate premises and organizational conditions for health promotion" and "readiness to promote health outside of workplace". Review of literature indicates that pharmacists play an important role in promoting health, especially when it comes to cardiovascular diseases (CVD), despite some barriers in pharmacistpatient communication [31]. Other obstacles related to CVD prevention and health education by pharmacists included a lack of educational materials [32]. The important factor in advising patients is adequate time. It can be neither too short because a patient may think the case is trivialized, nor too long because a patient may feel bored. On the other hand, a higher number of customers per pharmacist, or a desire to fill a prescription quickly may hamper proper counselling [33]. Insufficient time devoted by pharmacists was indicated as the main reason for patients' dissatisfaction with advice received from pharmacists in Korea [34]. Nevertheless, in the group of 252 patients and 620 pharmacists, $34 \%$ and $50 \%$, respectively, said they were satisfied with counselling. A Canadian study that investigated actual level of pharmacists' involvement in health promotion and disease prevention found that the major barriers included lack of: time, coordination with other professionals, staff and resources, and financial compensation [35]. 
Table 5 Assessment of pharmacy staff's readiness to promote heath versus pharmacy staff's and pharmacies' characteristics

\begin{tabular}{|c|c|c|c|c|c|c|}
\hline Characteristics of & Variable & Category, parameter & Systemic solutions & $\begin{array}{l}\text { Readiness of } \\
\text { professional } \\
\text { group }\end{array}$ & Personal readiness & Overall score \\
\hline \multirow[t]{15}{*}{ Pharmacy staff } & Total sample & $\mathrm{M} \pm \mathrm{SD}$ & $3.6 \pm 1.4$ & $4.8 \pm 1.8$ & $5.5 \pm 1.8$ & $4.6 \pm 1.5$ \\
\hline & \multirow[t]{3}{*}{ Gender } & Women, $\mathrm{M} \pm \mathrm{SD}$ & $3.7 \pm 1.4$ & $4.9 \pm 1.8$ & $5.5 \pm 1.8$ & $4.7 \pm 1.5$ \\
\hline & & Men, $M \pm S D$ & $2.7 \pm 1.0$ & $4.5 \pm 1.4$ & $5.7 \pm 1.5$ & $4.3 \pm 1.1$ \\
\hline & & $\mathrm{p}(\mathrm{t})$ & $<0.001$ & 0.247 & 0.555 & 0.168 \\
\hline & \multirow[t]{2}{*}{ Age (years) } & $\mathrm{r}$ & -0.163 & -0.145 & -0.222 & -0.199 \\
\hline & & $p$ & .004 & .011 & $<0.001$ & $<0.001$ \\
\hline & \multirow[t]{4}{*}{ Level of education } & $\begin{array}{l}\text { Pharmacy technicians, } \\
M \pm S D\end{array}$ & $4.4 \pm 1.6$ & $5.5 \pm 1.8$ & $5.9 \pm 2.0$ & $5.3 \pm 1.6$ \\
\hline & & $\begin{array}{l}\text { Masters of pharmacy } \\
M \pm S D\end{array}$ & $3.4 \pm 1.4$ & $4.7 \pm 1.9$ & $5.3 \pm 1.8$ & $4.5 \pm 1.5$ \\
\hline & & $\begin{array}{l}\text { Postgraduate education, } \\
\text { professional specializa- } \\
\text { tion or Ph.D., } M \pm S D\end{array}$ & $3.4 \pm 1.2$ & $4.7 \pm 1.5$ & $5.9 \pm 1.6$ & $4.7 \pm 1.2$ \\
\hline & & $p(\mathrm{~F})$ & $<0.001$ & .008 & .021 & .002 \\
\hline & \multirow[t]{5}{*}{ Job seniority (years) } & Below 5, $\mathrm{M} \pm \mathrm{SD}$ & $4.5 \pm 1.4$ & $5.9 \pm 1.5$ & $6.4 \pm 1.6$ & $5.6 \pm 1.3$ \\
\hline & & $5-14, M \pm S D$ & $3.1 \pm 1.2$ & $4.3 \pm 1.8$ & $5.2 \pm 2.0$ & $4.2 \pm 1.5$ \\
\hline & & $15-25, \mathrm{M} \pm \mathrm{SD}$ & $3.7 \pm 1.5$ & $4.6 \pm 1.4$ & $5.7 \pm 1.2$ & $4.7 \pm 1.2$ \\
\hline & & $>25, \mathrm{M} \pm \mathrm{SD}$ & $3.5 \pm 1.3$ & $5.0 \pm 1.8$ & $5.0 \pm 1.8$ & $4.5 \pm 1.4$ \\
\hline & & $p(\mathrm{~F})$ & $<0.001$ & $<0.001$ & $<0.001$ & $<0.001$ \\
\hline \multirow[t]{13}{*}{ Pharmacies } & \multirow[t]{4}{*}{ Number of staff } & Up to $3, \mathrm{M} \pm \mathrm{SD}$ & $4.1 \pm 1.5$ & $6.3 \pm 1.4$ & $7.1 \pm 1.4$ & $5.8 \pm 1.1$ \\
\hline & & $4-5, M \pm S D$ & $3.3 \pm 1.3$ & $4.4 \pm 1.8$ & $5.3 \pm 1.7$ & $4.4 \pm 1.5$ \\
\hline & & $>5, \mathrm{M} \pm \mathrm{SD}$ & $3.7 \pm 1.5$ & $4.7 \pm 1.7$ & $5.1 \pm 1.7$ & $4.5 \pm 1.4$ \\
\hline & & $p(\mathrm{~F})$ & .002 & $<0.001$ & $<0.001$ & $<0.001$ \\
\hline & \multirow[t]{5}{*}{ Location } & $\begin{array}{l}\text { Near a healthcare pro- } \\
\text { vider, } \mathrm{M}_{ \pm} \mathrm{SD}\end{array}$ & $3.6 \pm 1.2$ & $4.8 \pm 1.7$ & $5.5 \pm 1.8$ & $4.6 \pm 1.4$ \\
\hline & & $\begin{array}{l}\text { Urban area with high } \\
\text { pedestrian traffic, } \\
\mathrm{M} \pm \mathrm{SD}\end{array}$ & $3.7 \pm 1.7$ & $4.7 \pm 2.0$ & $5.5 \pm 1.9$ & $4.6 \pm 1.7$ \\
\hline & & Residential area, $\mathrm{M} \pm \mathrm{SD}$ & $3.3 \pm 1.6$ & $5.1 \pm 1.8$ & $5.8 \pm 2.1$ & $4.7 \pm 1.6$ \\
\hline & & Other, $\mathrm{M} \pm \mathrm{SD}$ & $3.5 \pm 1.7$ & $4.9 \pm 2.2$ & $5.6 \pm 1.8$ & $4.7 \pm 1.7$ \\
\hline & & $p(\mathrm{~F})$ & 0.497 & 0.718 & 0.864 & 0.995 \\
\hline & \multirow{4}{*}{$\begin{array}{l}\text { Daily average number } \\
\text { of clients in a phar- } \\
\text { macy }\end{array}$} & Below $100, \mathrm{M} \pm \mathrm{SD}$ & $3.2 \pm 1.2$ & $4.2 \pm 1.8$ & $4.9 \pm 2.0$ & $4.1 \pm 1.5$ \\
\hline & & $100-200, M \pm S D$ & $3.8 \pm 1.5$ & $5.1 \pm 1.8$ & $5.9 \pm 1.7$ & $4.9 \pm 1.5$ \\
\hline & & $>200, \mathrm{M} \pm \mathrm{SD}$ & $3.8 \pm 1.5$ & $5.1 \pm 1.5$ & $5.7 \pm 1.3$ & $4.9 \pm 1.3$ \\
\hline & & $p(\mathrm{~F})$ & .003 & $<0.001$ & $<0.001$ & $<0.001$ \\
\hline
\end{tabular}

Scale 1-10 where: 1 equaled to 'definitely no' and 10 equaled to 'definitely yes'

$M$ mean, $S D$ standard deviation, $r$ Pearson's correlation coefficient, $t$ Student's $t$ test for means in two unpaired samples, $F$ analysis of variance $F$ test for means in more than two unpaired samples

In our study female pharmacy staff rated systemic solutions for health promotion statistically significantly better than male pharmacy staff. In Poland, most pharmacists are women (almost 83\% pharmacists and 95\% pharmacy technicians according to Zappa Report [26]), as in our sample. Another finding was that the age of pharmacy staff surveyed was associated with some of the ratings-the younger the persons the better they rated readiness to promote health. This may be due to the fact that youths are more socially aware, modern educated, with better access to information, full of enthusiasm and less routine. Systemic solutions, readiness of pharmacy staff as a professional group and the overall readiness were rated higher by pharmacy staff with a secondary level of education. There were no correlations between pharmacy location and overall readiness, systemic solutions, readiness of pharmacy staff as a professional group and personal readiness to promote health.

The increasing role of pharmacists led to develop a new term-Pharmaceutical Public Health [36]. It is defined as pharmacists' input into social health by application of their 
knowledge and skills to prevent diseases, prolong life, promote, protect and improve health. The Pharmaceutical Public Health services should be as important as pharmaceutical care in the healthcare systems. However, it is crucial to properly identify health needs of people in order to develop the concept of Pharmaceutical Public Health.

There is a need in Poland to implement a modern system of pharmaceutical services that would take into account a unique role of a pharmacy as a point of delivering health services. Such implementation requires, proper legal regulations complemented with organizational and financial mechanisms. The results of our research indicate the need for pharmacy staff's education in the field of health promotion and health education. In our opinion, this education should already begin at university. The study by Rodis et al. [37] demonstrated that students from pharmacy schools in the USA, who were educated in the field of health promotion, positively evaluated this education program. Moreover, pharmacy students from Gdańsk (Poland) were found to correctly understand the concept of "public health" [38]. The students' knowledge of this topic, according to their self-assessment, was at an average level. Interestingly, the students assessed the involvement of pharmacists in the protection of public health as insufficient [38]. Currently, a great commitment from pharmacy students throughout Poland in health-promoting campaigns can be observed. During such events, students demonstrate how to measure blood pressure or blood glucose correctly. The importance of health promotion and disease prevention is especially visible during an epidemic status. The prevention of e.g. a virus spreading minimizes the number of cases and, in turn, does not cripple the health service.

The strength of our study is a sizeable study sample in which we evaluated the systemic solutions, readiness of pharmacy staff as a professional group, self-assessment of pharmacy staff's personal readiness to promote health and to perform health education.

Our study was performed within one region of Poland. However, our sample is representative in terms of the manner/conditions of functioning and legal acts as well as gender of pharmacy staff.

A lack of opportunity for open responses on how pharmacy staff really see their role in health promotion, whether they want to perform such activities and what they believe are the biggest barriers for ideal health education may be one of the study's limitation. We also did not ask surveyed pharmacists about the role they play in the pharmacy; it is not therefore clear how many of them were owners of pharmacies or pharmacy managers. Another limitation of our study is a lack of assessment of the demands and expectations of various groups of patients/customers of pharmacies regarding health promotion and education by pharmacy staff. However, it will be a perfect complement to our future research.

\section{Conclusions}

General readiness of pharmacy staff to promote health was low-significantly below the scale midpoint. The lowest ratings referred to systemic solutions for health promotion while the highest to personal readiness to promote health. Readiness of pharmacy staff as a professional group ranked in the middle. Pharmacy personnel surveyed in the study rated the readiness to promote health in work a environment to a greater extent than in the local community. Women, younger respondents, respondents with job seniority below 5 years and respondents with secondary education assessed their readiness to promote health better than others. Readiness to promote health was higher among pharmacy staff working in pharmacies employing up to 3 staff members and at pharmacies with over 200 customers daily.

Acknowledgements The authors thank Marek Jantos, Ph.D. for his involvement in English language improvement.

Funding The authors had no funding with this study.

Conflicts of interest The authors declare no conflict of interests.

Open Access This article is licensed under a Creative Commons Attribution 4.0 International License, which permits use, sharing, adaptation, distribution and reproduction in any medium or format, as long as you give appropriate credit to the original author(s) and the source, provide a link to the Creative Commons licence, and indicate if changes were made. The images or other third party material in this article are included in the article's Creative Commons licence, unless indicated otherwise in a credit line to the material. If material is not included in the article's Creative Commons licence and your intended use is not permitted by statutory regulation or exceeds the permitted use, you will need to obtain permission directly from the copyright holder. To view a copy of this licence, visit http://creativecommons.org/licenses/by/4.0/.

\section{References}

1. Moltó-Puigmartí C, Vonk R, van Ommeren G, Hegger I. A logic model for pharmaceutical care. J Health Serv Res Policy. 2018;23(3):148-57.

2. Tsuyuki RT, Beahm NP, Okada H, Al Hamarneh YN. Pharmacists as accessible primary health care providers: review of the evidence. Can Pharm J (Ott). 2018;151(1):4-5.

3. Kennie-Kaulbach N, Farrell B, Ward N, Johnston S, Gubbels A, Eguale T, Dolovich L, Jorgenson D, Waite N, Winslade N. Pharmacist provision of primary health care: a modified Delphi validation of pharmacists' competencies. BMC Fam Pract. 2012;13(27):1-9.

4. Burak J, Anders S, Karpińska J, Gąsior J, Fedorowicz O. Participation of pharmacists in cancer patient's care. Farmacja Współczesna. 2015;8:21-8 (in Polish).

5. Lai E, Trac L, Lovett A. Expanding the pharmacist's role in public health. Univers J Public Health. 2013;1:79-85.

6. Mohamed SS, Mahmoud AA, Ali AA. Involvement of Sudanese community pharmacists in public health activities. Int $\mathrm{J}$ Clin Pharm. 2013;35(3):393-400. 
7. Goad JA, Taitel MS, Fensterheim LE, Cannon AE. Vaccinations administered during off-clinic hours at a national community pharmacy: implications for increasing patient access and convenience. Ann Fam Med. 2013;11(5):429-36.

8. American Pharmacists Association. American Pharmacists Association Annual Report; 2017.

9. Westrick SC, Patterson BJ, Kader MS, Rashid S, Buck PO, Rothholz MC. National survey of pharmacy-based immunization services. Vaccine. 2018;36(37):5657-64.

10. Isenor JE, Edwards NT, Alia TA, Slayter KL, MacDougall DM, McNeil SA, Bowles SK. Impact of pharmacists as immunizers on vaccination rates: a systematic review and meta-analysis. Vaccine. 2016;34(47):5708-23.

11. Jones EJ, Mackinnon NJ, Tsuyuki RT. Pharmaceutical care in community. pharmacies: practice and research in Canada. Ann Pharmacother. 2005;39(9):1527-33.

12. Piecuch A, Kozłowska-Wojciechowska M. Self-medication in Poland: the pharmacist's advisory role in Warsaw. Int J Clin Pharm. 2013;35(2):225-9.

13. Community Pharmacy Contractual Framework 2019-2024. London; 2019. https://assets.publishing.service.gov.uk/government /uploads/system/uploads/attachment_data/file/819601/cpcf2019-to-2024.pdf. Accessed 21 Apr 2020.

14. Scottish Executive. New community pharmacy contract update, HDL, 36. Edinburgh; 2004. http://www.sehd.scot.nhs.uk/mels/ HDL2004_36.pdf. Accessed 21 Apr 2020.

15. Root G, Varney J. Pharmacy: A Way Forward for Public Health.\&nbsp;Opportunities for action through pharmacy for public health. London: Public Health England; 2017.

16. Retail Pharmacy in Europe Strategy, Pharmaceutical Group of European Union 2012.

17. The Pharmaceutical Law of September 6, 2001 (consolidated text, Dz.U. of 2017, item 2211, as amended) (in Polish).

18. Blanchet F. Role of community pharmacists in obesity prevention and support to patients. Bull Acad Natl Med. 2015;199(8-9):1291-303.

19. Um IS, Krass I, Armour C, Gill T, Chaar BB. Developing and testing evidence-based weight management in Australian pharmacies: a Healthier Life Program. Int J Clin Pharm. 2015;37(5):822-33.

20. Morillo-Verdugo R, Robustillo-Cortés MLA, Martín-Conde MT, Callejón-Callejón G, Cid-Silva P, Moriel-Sánchez C, TortajadaGoitia B, Almeida-González CV. Effect of a structured pharmaceutical care intervention versus usual care on cardiovascular risk in HIV patients on antiretroviral therapy: INFAMERICA study. Ann Pharmacother. 2018;52(11):1098-108.

21. Dirks-Naylor AJ, Griffiths CL, Bush MA. Exercise is medicine: student pharmacists' perceptions and knowledge of exercise prescription. Adv Physiol Educ. 2018;42(2):289-94.

22. Subramaniam V, Sierra J. Pharmacists' impact on public health. Drug Top. 2013;8:157.

23. Chiu YL, Liang JC, Mao PC, Tsai CC. Improving health care providers' capacity for self-regulated learning in online continuing pharmacy education: the role of internet self-efficacy. J Contin Educ Health Prof. 2016;36(2):89-95.
24. Mohamed Ibrahim OH. Assessment of Egyptian pharmacists' attitude, behaviors, and preferences related to continuing education. Int J Clin Pharm. 2012;34(2):358-63.

25. Act of 7 April 2017 amending the Act.-Pharmaceutical Law (Dz.U. 2017, item 1015) (in Polish).

26. Pharmacies in Poland-Report 2019. http://aptekarze.org.pl/wpcontent/uploads/2019/05/.

27. Gaś Z. Procedures for constructing early intervention programs. In: Psycho prevention. Lublin: Wydawnictwo Uniwersytetu Marii Curie-Skłodowskiej; 2000 (in Polish).

28. O'Loughlin J, Masson P, Déry V, Fagnan D. The role of community pharmacists in health education and disease prevention: a survey of their interests and needs in relation to cardiovascular disease. Prev Med. 1999;28(3):324-31.

29. Awad A, Abahussain E. Health promotion and education activities of community pharmacists in Kuwait. Pharm World Sci. 2010;32(2):146-53.

30. Baseer MA, Mehkari MA, Al-Marek FA, Bajahzar OA. Oral health knowledge, attitude, and self-care practices among pharmacists in Riyadh, Riyadh Province, Saudi Arabia. J Int Soc Prev Community Dent. 2016;6(2):134-41.

31. Alonso-Perales MDM, Lasheras B, Beitia G, Beltrán I, Marcos B, Núñez-Córdoba JM. Barriers to promote cardiovascular health in community pharmacies: a systematic review. Health Promot Int. 2017;32(3):535-48.

32. El Hajj MS, Mahfoud ZR, Al Suwaidi J, Alkhiyami D, Alasmar AR. Role of pharmacist in cardiovascular disease-related health promotion and in hypertension and dyslipidemia management: a cross-sectional study in the State of Qatar. J Eval Clin Pract. 2016;22(3):329-40.

33. O'Donnell DC, Brown CM, Dastani HB. Barriers to counseling patients with obesity: a study of Texas community pharmacists. J Am Pharm Assoc. 2006;46(4):465-71.

34. Yang S, Kim D, Choi HJ, Chang MJ. A comparison of patients' and pharmacists' satisfaction with medication counseling provided by community pharmacies: a cross-sectional survey. BMC Health Serv Res. 2016;16:131.

35. Laliberté MC, Perreault S, Damestoy N, Lalonde L. Ideal and actual involvement of community pharmacists in health promotion and prevention: a cross-sectional study in Quebec, Canada. BMC Public Health. 2012;12:192.

36. Walker R. Pharmaceutical public health: the end of pharmaceutical care? Pharm J. 2000;264:340-1.

37. Rodis JL, Ulbrich TR, Jennings BT, Elswick BM, McKinley RJ. Students as catalysts to increase community pharmacy-led direct patient care services. J Am Pharm Assoc. 2015;55(6):642-8.

38. Susłowska N, Petrykowski B, Zimmermann A, Balwicki Ł. Pharmacist role in the public health-pharmacy students perception. Farm Pol. 2018;74(4):191-8 (in Polish). 